\title{
openheart Impact of pregnancy and risk factors for ventricular arrhythmias in women with tetralogy of Fallot
}

Alessia Quattrone (1) , ${ }^{1,2}$ Oyvind H Lie, ${ }^{1,2}$ Eirik Nestaas, ${ }^{3}$ Charlotte de Lange, ${ }^{4,5}$ Kirsti Try, ${ }^{4}$ Harald L Lindberg, ${ }^{6}$ Helge Skulstad, ${ }^{1,2}$ Gunnar Erikssen, ${ }^{1}$ Thor Edvardsen, ${ }^{1,2}$ Kristina Haugaa (1) , ${ }^{1,2}$ Mette E Estensen ${ }^{1,2}$

To cite: Quattrone $\mathrm{A}$, Lie $\mathrm{OH}$, Nestaas E, et al. Impact of pregnancy and risk factors for ventricular arrhythmias in women with tetralogy of Fallot. Open Heart 2021;8:e001400. doi:10.1136/ openhrt-2020-001400

Received 19 August 2020 Revised 20 November 2020 Accepted 7 December 2020

Check for updates

(c) Author(s) (or their employer(s)) 2021. Re-use permitted under CC BY-NC. No commercial re-use. See rights and permissions. Published by BMJ.

'Department of Cardiology, 0slo University Hospital, Oslo, Norway 2University of Oslo, Oslo, Norway ${ }^{3}$ Department of Paediatrics, Vestfold Hospital Trust, Tønsberg, Norway

${ }^{4}$ Division of Radiology and Nuclear Medicine, Section of Pediatric Radiology, Oslo University Hospital, Oslo, Norway ${ }^{5}$ Sahlgrenska University Hospital, Goteborg, Sweden ${ }^{6}$ Department of Cardiothoracic Surgery, Oslo University Hospital, Oslo, Norway

Correspondence to Dr Mette E Estensen; mestense@ous-hf.no

\section{ABSTRACT}

Objective Patients with tetralogy of Fallot (TOF) have high survival rates 30 years after surgical repair. Many patients experience pregnancy; however, the effects of pregnancy on the long-term cardiovascular outcome are not well known. We investigated the association of pregnancy and cardiac function with occurrence of ventricular arrhythmia (VA) in women with TOF.

Methods We recruited 80 women with repaired TOF from the national database. Holter monitoring or implanted devices detected VA, defined as non-sustained or sustained ventricular tachycardia or aborted cardiac arrest. All patients underwent echocardiography. Blood tests included NT-proBNP (N-terminal pro-brain natriuretic peptide).

Results 55 (69\%) women had experienced pregnancy. Mean age was lower in nulliparous compared with those with children ( $30 \pm 9$ vs $40 \pm 9, p<0.01$ ).

VA had occurred in 17 (21\%) women. Prevalence of VA was higher in women who had experienced pregnancy $(\mathrm{n}=16,94 \%)$ compared with nulliparous $(\mathrm{n}=1,6 \%)$ $(\mathrm{p}=0.02)$, also when adjusted for age (OR $12.9(95 \% \mathrm{Cl} 1.5$ to 113.2), $p=0.02$ ).

Right ventricular mechanical dispersion was more pronounced in patients with VA ( $50 \pm 8 \mathrm{~ms}$ vs $39 \pm 14 \mathrm{~ms}$, $p=0.01$, age-adjusted OR 2.1 (95\% Cl 1.3 to 7.5$), p=0.01$ ). NT-proBNP was also a marker of VA (211 ng/L (127 to 836) vs $139 \mathrm{ng} / \mathrm{L}$ (30 to 465), $\mathrm{p}=0.007$ ). NT-proBNP $>321 \mathrm{ng} / \mathrm{L}$ (normal values $<170 \mathrm{ng} / \mathrm{L}$ ) detected women with VA $(p=0.019)$, also independent of age (OR 7.2 (95\% Cl 1.7 to 30.1), $p=0.007$ ).

Conclusion Pregnancy was associated with higher prevalence of VA among women with TOF. Right ventricular mechanical dispersion and NT-proBNP were ageindependent markers of VA. These may have importance for pregnancy counselling and risk stratification.

\section{INTRODUCTION}

Tetralogy of Fallot (TOF) is one the most common cyanotic congenital heart diseases. In the present era of cardiac surgery, patients with TOF enjoy a satisfactory quality of life and a survival rate of about $93 \% 20$ years after corrective surgery, $80 \% 30$ years after repair ${ }^{12}$ and $72 \%$ after 40 years. ${ }^{3}$ The most

\section{Key questions}

What is already known about this subject?

- Previous studies showed a higher risk of arrhythmias in patients operated on for tetralogy of Fallot with 12-lead ECG as the main tool used for risk stratification.

- Other studies that investigated the short-term outcome of pregnancy in women operated on for tetralogy of Fallot indicated a higher prevalence of ventricular and supraventricular arrhythmias, heart failure and right ventricular dilation.

What does this study add?

- This study provides an insight on the influence of pregnancy on the long-term outcome in women corrected for tetralogy of Fallot.

- Our investigation showed that pregnancy was associated with higher prevalence of ventricular arrhythmias in women operated on for tetralogy of Fallot, independently of age.

- Furthermore, our study showed that higher values of right ventricular mechanical dispersion and $\mathrm{N}$ terminal pro-brain natriuretic peptide (NT-proBNP) were age-independent risk markers of ventricula arrhythmias.

How might this impact on clinical practice?

- The knowledge about association between pregnancy and higher risk of ventricular arrhythmias might become important in preconceptional counselling of those patients.

- NT-proBNP and right ventricle mechanical dispersion might become parameters to consider in risk stratification in patients operated on for tetralogy of Fallot.

common cause of death in patients with surgically corrected TOF is sudden cardiac death $(49 \%)$, heart failure $(27 \%)$ and coronary artery disease $(6 \%) .^{34}$

The high risk of arrhythmias in patients with TOF is well known and documented in previous large studies. ${ }^{3} 4$ The risk stratification is currently mostly based on 12-lead ECG with QRS duration $>180 \mathrm{~ms}$ and QRS rate 
change as risk markers of sudden cardiac death; pulmonary regurgitation and older age at repair are associated with adverse cardiac events. ${ }^{4}$ However, risk stratification is insufficient and better methods are warranted. Myocardial deformation indices have recently shown to be useful in risk stratification in patients with $\mathrm{TOF}^{5}$

Most of the patients with TOF reach adulthood, and consequently many female patients want to give childbirth. During normal pregnancy, the cardiovascular system adapts to the metabolic needs of mother and fetus in order to adequately perfuse tissues with oxygenated blood by increasing cardiac output by $30 \%-50 \%$, increasing heart rate by $10-20$ beats per minute and decreasing peripheral vascular resistance by $30 \%{ }^{6}$ Myocardial contractility in normal pregnancy has been found altered in some studies but not in other. ${ }^{78}$ The impact of these haemodynamic and myocardial changes during pregnancy in women operated on for TOF are still not well known.

Several studies have focused on short-term outcome of pregnancy in women with TOF and indicated a higher rate of cardiovascular events, including ventricular and supraventricular arrhythmias, ${ }^{9}$ heart failure and progressive right ventricular (RV) dilation. ${ }^{10}$ However, it is not known if the pregnancy-induced cardiovascular alterations influence long-term cardiovascular outcome. Importantly, no previous studies have investigated the association of pregnancy in the general risk stratification, in particular on the occurrence of ventricular arrhythmias (VAs).

The aim of our study was to investigate the influence of one or more pregnancies on cardiac function and occurrence of VA in women corrected for TOF. We hypothesised that the prolonged haemodynamic stress of pregnancy is associated with adverse outcome in patients with TOF, including VA and heart failure.

\section{METHODS}

\section{Study population}

We included patients diagnosed for TOF recruited from our centre's patient GUCH registry. This database included all patients followed at Oslo University Hospital, Rikshospitalet, Norway from 1953 to 2017.

We selected female patients $>18$ years of age who had been previously corrected for TOF; 80 patients were contacted with an information letter. We recruited patients with all forms of surgical repair, including those who had undergone a palliative operation as Waterstone or Blalock-Taussig shunt some months or years prior to surgical correction. Patients with history of pregnancy were recruited only if delivery had occurred at least 1 year prior to inclusion. Patients unable to give informed consent and patients with delivery occurred $<1$ year of time were excluded.

All patients approached to be involved in the study agreed to participate. Most patients agreed to the direct inclusion and underwent a structured study protocol, while the remaining subjects who chose not to participate to the active recruitment consented to the use of registry data within 3years (2015-2017). All participants gave written informed consent. Medical records and echocardiographic exams available in the hospital electronic medical record system were reviewed. The study complied with the Declaration of Helsinki and was approved by the Regional Committees for Medical Research Ethics (reference number 2017/383).

This research was conducted without patient involvement in the study design, interpretation of results and writing this manuscript. The research project was presented to the Norwegian Association of Adults with Congenital Heart Diseases (VMH, Voksne med medfødt hjertefeil) prior to the initiation.

\section{Electrocardiography and arrhythmias}

An ECG and 24-hour Holter monitoring was obtained in all participants at the same visit as the echocardiographic examination. The history of VA was assessed from ECG, 24-hour Holter registration and implantable cardioverterdefibrillator (ICD) monitoring.

We considered clinically relevant VA as non-sustained ventricular tachycardia (NSVT), defined as consecutive runs of $\geq 3$ ventricular beats $>100$ beats $/$ min for $<30 \mathrm{~s}$; sustained ventricular tachycardia (SVT), defined as runs of consecutive ventricular beats $>100$ beats for $>30 \mathrm{~s},{ }^{11}$; ventricular fibrillation (VF), appropriate therapy from an ICD; and aborted cardiac arrest (CA). We recorded age at first documented arrhythmic event.

\section{Cardiopulmonary exercise test}

All patients included in the study had undergone a cardiopulmonary exercise test, either during the active recruitment or during their annual follow-up at GUCH outpatient clinic. The exercise stress test was performed on a bicycle ergometer using Bruce protocol. ${ }^{12}$ Oxygen saturation, heart rate and 12-lead ECG were continuously recorded, and cuff blood pressure was measured every second minute.

\section{Echocardiographic study}

The echocardiographic study was performed on a Vivid E95 (GE Healthcare, Horten, Norway) and data were analysed off-line (EchoPAC V.201; GE Healthcare).

From 2D echocardiography, we assessed proximal right ventricular outflow tract (RVOT) diameter in the parasternal short axis view, and right ventricular (RV) basal diameter and right ventricular fractional area change (RVFAC) in the RV focused four-chamber view. ${ }^{13}$ Regional RV akinesia and/or dyskinesia were detected in parasternal long-axis or short-axis view and RV focused four-chamber view.

Left ventricular (LV) ejection fraction was calculated by the modified Simpson's biplane method. ${ }^{14}$ Myocardial function was further assessed by global longitudinal strain (GLS) using speckle tracking technique, ${ }^{15}$ at frame rates between 80 and 100/s. RV longitudinal strain was 
Table 1 Clinical characteristics and echocardiographic parameters in female patients corrected for TOF grouped by parity

\begin{tabular}{|c|c|c|c|c|c|c|}
\hline & $\begin{array}{l}\text { TOF } \\
\mathrm{n}=80\end{array}$ & $\begin{array}{l}\text { TOF without children } \\
(n=25)\end{array}$ & $\begin{array}{l}\text { TOF with children } \\
(n=55)\end{array}$ & $P$ value & $\begin{array}{l}\text { OR } \\
(95 \% \mathrm{Cl})\end{array}$ & $P$ value \\
\hline Age, years & $37 \pm 10$ & $30 \pm 9$ & $40 \pm 9$ & $<0.01$ & & \\
\hline Height, cm & $165 \pm 7$ & $165 \pm 7$ & $165 \pm 7$ & 0.96 & & \\
\hline Weight, kg & $68 \pm 13$ & $67 \pm 11$ & $69 \pm 13$ & 0.53 & & \\
\hline $\mathrm{HR}, \mathrm{bpm}$ & $69 \pm 13$ & $73 \pm 10$ & $67 \pm 13$ & 0.07 & & \\
\hline Transannular patch (\%) & $30(37)$ & $11(44)$ & $19(36)$ & 0.53 & & \\
\hline $\mathrm{SBP}, \mathrm{mm} \mathrm{Hg}$ & $116 \pm 11$ & $115 \pm 9$ & $117 \pm 12$ & 0.59 & & \\
\hline $\mathrm{DBP}, \mathrm{mm} \mathrm{Hg}$ & $71 \pm 10$ & $72 \pm 8$ & $70 \pm 11$ & 0.50 & & \\
\hline QTc duration, ms & $460 \pm 31$ & $460 \pm 29$ & $460 \pm 32$ & 0.96 & & \\
\hline Exercise capacity, W & $131 \pm 27$ & $127 \pm 24$ & $132 \pm 28$ & 0.53 & & \\
\hline NYHA class & $1(1-3)$ & $1(1-3)$ & $1(1-3)$ & 0.11 & & \\
\hline NT-ProBNP, ng/L & $174(30-836)$ & $110(30-372)$ & $198(49-836)$ & 0.11 & & \\
\hline QRS duration, ms & $132(82-174)$ & $124(86-162)$ & $134(82-174)$ & 0.62 & & \\
\hline RV EDV, $\mathrm{mL}$ & $21.7 \pm 4.6$ & $20.5 \pm 4.8$ & $21.9 \pm 4.0$ & 0.18 & & \\
\hline RV ESV, mL & $11.3 \pm 2.9$ & $10.8 \pm 2.9$ & $11.3 \pm 2.7$ & 0.52 & & \\
\hline RV FAC, $\%$ & $47.8 \pm 7.2$ & $47.1 \pm 7.4$ & $48.1 \pm 7.3$ & 0.58 & & \\
\hline $\mathrm{RV}$ D3, cm & $7.3 \pm 0.7$ & $7.1 \pm 0.7$ & $7.4 \pm 0.7$ & 0.03 & 2.1 (1.1 to 4.3$)$ & 0.04 \\
\hline PV vel, $\mathrm{m} / \mathrm{s}$ & $1.9 \pm 0.6$ & $1.9 \pm 0.7$ & $1.9 \pm 0.5$ & 0.91 & & \\
\hline Mod-sev PV reg & $14(17 \%)$ & $5(22 \%)$ & $9(16 \%)$ & 0.48 & & \\
\hline LV MD, ms & $43.3 \pm 14$ & $41.4 \pm 10$ & $45.3 \pm 10$ & 0.4 & & \\
\hline LV GLS, \% & $-18.9 \pm 3.3$ & $-19.2 \pm 3.1$ & $-17.5 \pm 3.6$ & 0.1 & & \\
\hline RV MD, ms & $42 \pm 13$ & $38 \pm 12$ & $43 \pm 14$ & 0.1 & & \\
\hline RV GLS, \% & $-19.1 \pm 4.1$ & $-19.7 \pm 4.1$ & $-18.3 \pm 4.1$ & 0.28 & & \\
\hline RVOT, cm & $2.9 \pm 0.5$ & $2.9 \pm 0.4$ & $3.1 \pm 0.6$ & 0.31 & & \\
\hline LVEF, \% & $55 \pm 8$ & $56 \pm 8$ & $54 \pm 8$ & 0.39 & & \\
\hline
\end{tabular}

Data are presented as mean $\pm S D$ or median with range, as appropriate; $p$ value from Student's t-test, Mann-Whitney $U$ or $\chi^{2}$ test as appropriate, and multivariable logistic regression adjusted for age.

DBP, diastolic blood pressure; EDV, end-diastolic volume; ESS, end-systolic strain; ESV, end-systolic volume; GLS, global longitudinal strain; HR, heart rate; LV, left ventricular; LVEF, left ventricular ejection fraction; MD, mechanical dispersion; NT-proBNP, N-terminal pro-brain natriuretic peptide; NYHA, New York Heart Association classification; PV, pulmonary valve; RV, right ventricular; RV D3, right ventricular longitudinal diameter; RV FAC, right ventricular fractional area change; RVOT, right ventricular outflow tract; SBP, systolic blood pressure; TOF, tetralogy of Fallot; VA, ventricular arrhythmia.

defined as an average peak negative systolic longitudinal strain from six RV segments. ${ }^{16} 17$ LV global longitudinal strain was defined as the average of peak systolic negative longitudinal deformation/strain from a 16-segment LV model. $^{15}$

Mechanical dispersion, which is defined as the SD of the time interval from onset of the $\mathrm{Q} / \mathrm{R}$ wave in the ECG to the peak negative longitudinal strain in $6 \mathrm{RV}$ and 16 LV segments, was calculated as a measure of contraction heterogeneity. ${ }^{17}$

Pulmonary valve stenosis and pulmonary valve regurgitation of moderate to severe grade were also assessed and considered.

\section{Biochemistry}

Blood tests included N-terminal pro-brain natriuretic peptide (NT-proBNP) measurement, with reference values $<170 \mathrm{ng} / \mathrm{L}$. NT-proBNP concentration in plasma were assayed on a Modular platform (Roche Diagnostics, Basel, Switzerland).

\section{Statistical analysis}

Statistical analysis was performed by using IBM SPSS V.25. Data are presented as mean \pm SD or median with range, as appropriate. Comparisons of continuous data were performed by the unpaired Student's t-test or MannWhitney $\mathrm{U}$ test, or by the ANOVA F-test and the Bonferroni post hoc correction when more than two groups were compared. Categorical variables were compared by the $\chi^{2}$ test or Fisher's exact test as appropriate. The odd of VA in patients with previous pregnancy versus those without pregnancy was assessed by logistic regression, and the effect of increasing number of pregnancies was analysed separately. Multivariable logistical regression was performed retaining covariates of interest from univariable analyses, after controlling for multicollinearity. We 


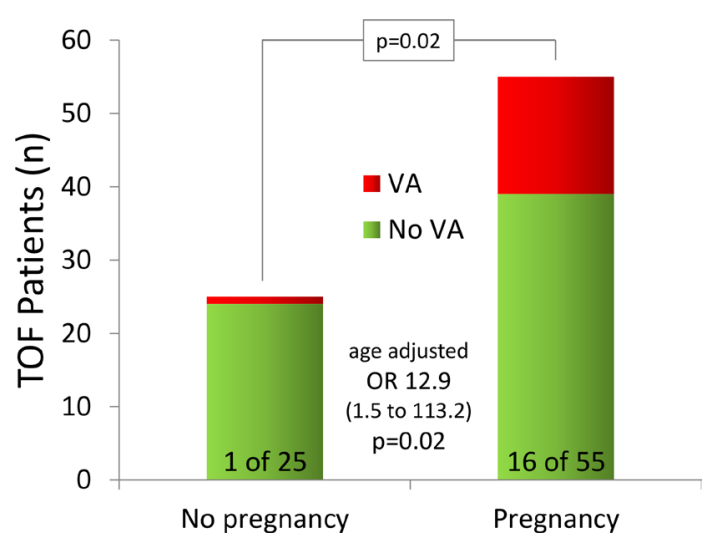

Figure 1 Pregnancy and risk of ventricular arrhythmias. Prevalence of VA was higher in female patients corrected for TOF with history of pregnancy, also when adjusted for age at arrhythmic event. The red coloured segments of two columns show that VA was significantly more represented in women who had experienced pregnancy compared with nulliparous. TOF, tetralogy of Fallot; VA, ventricular arrhythmia.

adjusted for age using logistic regression, having pregnancy and age at arrhythmic event used as covariates in the logistic regression analysis. We used Akaike's information criterion (AIC) to assess overfitting by the tradeoff of added complexity and precision in the regression models, and increasing values suggested inferior models. The optimal threshold of NT-proBNP to detect VA was assessed using a single threshold regression (STATA SE V.15.1; StataCorp, Texas, USA). By Kaplan-Meier curves, we showed the incidence of VA according to this. $\mathrm{P}$ values $\leq 0.05$ were considered statistically significant.

\section{RESULTS}

\section{Clinical characteristics}

We included 80 female patients corrected for TOF recruited from our centre's patient GUCH registry, of which 55 participated in active recruitment and 25 gave consent to the use of registry data.

In all, $55(69 \%)$ women had experienced pregnancy (age $40 \pm 9$ years, median parity 1 , range $1-4$ ), while 25 $(31 \%)$ were nulliparous. Mean age was lower in nulliparous women compared with those with children $(31 \pm 9$ years vs $40 \pm 9$ years, $\mathrm{p}<0.01)$. Nineteen mothers had 1 child, 28 had 2 children and 8 had $>2$ children.

Use of transannular RVOT reconstruction with patch as corrective surgery was registered in 30 patients, of which 11 (44\% of 25 patients) were nulliparous and $19(36 \%$ of 55 patients) had experienced pregnancy $(\mathrm{p}=0.53$, table 1). Information on type of surgery was not available for three patients.

\section{Electrocardiography, exercise capacity and arrhythmias}

VA had occurred in 17 (21\%) women, and was more prevalent in women who had experienced pregnancy compared with nulliparous $(\mathrm{n}=16(94 \%)$ vs $\mathrm{n}=1(6 \%)$, $\mathrm{p}=0.02$ ).
Of the 17 women with VA, 9 had NSVT detected at 24-hour Holter monitoring, while 8 had clinical events as consequence of $\mathrm{VT}$ or $\mathrm{VF} / \mathrm{CA}$. Among the nine patients with NSVT, in three of them the presence of inducible VT was confirmed by electrophysiological study; those patients underwent subsequently ICD implantation.

Due to suspected confounding, we adjusted for age at event using logistic regression. Importantly, VA was more prevalent in women with children also when adjusted for age at arrhythmic event (OR 12.9 (95\% CI 1.5 to 113.2), $\mathrm{p}=0.02$ ) (table 1, figure 1). All arrhythmic events occurred after pregnancy, with the exception of one patient who received ICD implantation in her mid-twenties due to symptomatic sustained ventricular tachycardia. About 5 years after ICD implantation, this patient became pregnant and delivered without any reported complications. The prevalence remained statistically significant also when this patient was excluded from the statistical analysis ( $\mathrm{p}=0.01$, OR 11.3 (95\% CI 1.3 to 99.5 ), $\mathrm{p}=0.02$ adjusted for age at the arrhythmic event).

There was a trend of increasing odds of VA for every additional pregnancy, but this model had signs of overfitting (OR 1.6 (95\% CI 0.9 to 2.7), $\mathrm{p}=0.06$, AIC increased from 79 to 83) (table 2).

Mean age was similar between patients with and without VA ( $40 \pm 9$ years vs $36 \pm 9$ years, $\mathrm{p}=0.08$, table 3 ).

ECG QRS width did not differ between nulliparous and women with children (table 1) and was not associated with VA (table 3 ). There were no differences in exercise capacity $(127 \pm 24 \mathrm{~W}$ in nulliparous vs $132 \pm 28 \mathrm{~W}$ in women with children, $\mathrm{p}=0.53)$.

\section{RV and LV function and morphology}

We did not observe any difference in RV end-diastolic and end-systolic volumes, fractional area change and the $\mathrm{RV}$ outflow tract dimension, as well as in pulmonary valve stenosis and regurgitation grade and in LV parameters, including strain and mechanical dispersion, in women who had experienced pregnancy (table 1) compared with nulliparous women. The longitudinal diameter of the RV (D3) was, however, greater in women who had been pregnant $(\mathrm{p}=0.03$, table 1$)$.

RV mechanical dispersion was significantly higher in patients with VA $(0.050 \pm 0.008 \mathrm{~s}$ vs $0.039 \pm 0.014 \mathrm{~s}, \mathrm{p}=0.009)$, also when adjusted for age at VA (OR 2.1 (95\% CI 1.3 to $7.5), \mathrm{p}=0.01)$ and age at echocardiography (OR 5.7 (95\% CI 3.5 to 9.2), $\mathrm{p}=0.03$ ) (table 3). Other parameters of left and right ventricular function or diameters did not differ between women with and without VA.

NT-proBNP and RV mechanical dispersion had a very weak correlation ( $p=0.02$, with $\left.\mathrm{R}^{2} 0.082\right)$. NT-proBNP was higher and above reference value in patients with VA ( $211 \mathrm{ng} / \mathrm{L}$ (127 to 836 ) vs $139 \mathrm{ng} / \mathrm{L}$ (30 to 465 ), $\mathrm{p}=0.007$ ), and remained as a significant marker of VA when adjusted for age (adjusted OR 1.4 (95\% CI 1.1 to 1.7 ) by 50-unit increments, $\mathrm{p}=0.009$ ). Threshold regression suggested an optimal differentiation level of NT-proBNP of $321 \mathrm{ng} / \mathrm{L}$. Kaplan-Meier survival analyses showed better freedom 
Table 2 Clinical characteristics and echocardiographic parameters in female patients corrected for TOF grouped by number of pregnancies

\begin{tabular}{|c|c|c|c|c|c|c|}
\hline & $\begin{array}{l}0 \\
\text { pregnancy } n=25 \\
(31 \%)\end{array}$ & $\begin{array}{l}1 \\
\text { pregnancy } n=19 \\
(24 \%)\end{array}$ & $\begin{array}{l}>1 \\
\text { pregnancy } n=36 \\
(45 \%)\end{array}$ & $P$ value & $\begin{array}{l}\text { OR } \\
(95 \% \mathrm{Cl})\end{array}$ & $P$ value \\
\hline Age, years & $29 \pm 10$ & $38 \pm 11$ & $40 \pm 7$ & $<0.01$ & & \\
\hline Height, cm & $165 \pm 7$ & $166 \pm 4$ & $165 \pm 7$ & 0.55 & & \\
\hline Weight, kg & $67 \pm 11$ & $63 \pm 6$ & $69 \pm 15$ & 0.55 & & \\
\hline $\mathrm{HR}, \mathrm{bpm}$ & $73 \pm 10$ & $63 \pm 13$ & $67 \pm 13$ & 0.23 & & \\
\hline SBP, mm Hg & $115 \pm 9$ & $111 \pm 14$ & $117 \pm 10$ & 0.84 & & \\
\hline DBP, $\mathrm{mm} \mathrm{Hg}$ & $71 \pm 7$ & $65 \pm 10$ & $71 \pm 11$ & 0.39 & & \\
\hline QTc duration, ms & $460 \pm 30$ & $458 \pm 30$ & $462 \pm 33$ & 0.83 & & \\
\hline Exercise capacity, W & $127 \pm 24$ & $131 \pm 25$ & $133 \pm 29$ & 0.82 & & \\
\hline NYHA class & $1(1-3)$ & $1(1-2)$ & $1(1-3)$ & 0.53 & & \\
\hline NT-ProBNP, ng/L & 109 (30-372) & $177(110-836)$ & $126(49-558)$ & 0.50 & & \\
\hline QRS duration, $\mathrm{ms}$ & $124(86-162)$ & $148(94-174)$ & $134(82-172)$ & 0.69 & & \\
\hline TOF with VA $(n=17)$ & $1(4 \%)$ & $6(31 \%)$ & $10(28 \%)$ & 0.04 & 2.4 (1.1 to 5.4$)$ & 0.03 \\
\hline RV EDV, mL & $20.5 \pm 4.8$ & $22.8 \pm 4.8$ & $21.7 \pm 4.1$ & 0.25 & & \\
\hline RV ESV, mL & $10.8 \pm 2.9$ & $12.1 \pm 3.7$ & $11 \pm 2.1$ & 0.33 & & \\
\hline RV FAC, $\%$ & $47 \pm 7$ & $46 \pm 8$ & $49 \pm 6$ & 0.46 & & \\
\hline RV D3, cm & $7.0 \pm 0.7$ & $7.6 \pm 0.9$ & $7.3 \pm 0.6$ & 0.05 & & \\
\hline PV vel, m/s & $1.9 \pm 0.7$ & $2.0 \pm 0.5$ & $1.8 \pm 0.5$ & 0.65 & & \\
\hline Mod-sev PV reg & $5(22 \%)$ & $3(15 \%)$ & $9(25 \%)$ & 0.76 & & \\
\hline LV MD, ms & $41 \pm 10$ & $45 \pm 11$ & $45 \pm 16$ & 0.59 & & \\
\hline LV GLS, \% & $-19.0 \pm 3.0$ & $-18.8 \pm 3.6$ & $-18.7 \pm 3.2$ & 0.95 & & \\
\hline RV MD, ms & $38 \pm 12$ & $43 \pm 16$ & $43 \pm 13$ & 0.41 & & \\
\hline RV GLS, \% & $-19.2 \pm 5.0$ & $-18.1 \pm 3.8$ & $-19.4 \pm 3.2$ & 0.54 & & \\
\hline RVOT, cm & $2.9 \pm 0.3$ & $3.2 \pm 0.5$ & $2.8 \pm 0.5$ & 0.07 & & \\
\hline LVEF, \% & $57 \pm 7$ & $56 \pm 9$ & $54 \pm 8$ & 0.39 & & \\
\hline
\end{tabular}

Data are presented as mean \pm SD or median with range, as appropriate; $p$ value from Student's t-test, Mann-Whitney $U, \chi^{2}$ test or ANOVA as appropriate, and multivariable logistic regression adjusted for age.

DBP, diastolic blood pressure; EDV, end-diastolic volume; ESS, end-systolic strain; ESV, end-systolic volume; GLS, global longitudinal strain; HR, heart rate; LV, left ventricular; LVEF, left ventricular ejection fraction; MD, mechanical dispersion; NT-proBNP, N-terminal pro-brain natriuretic peptide; NYHA, New York Heart Association classification; PV, pulmonary valve; RV, right ventricular; RV D3, right ventricular longitudinal diameter; RV FAC, right ventricular fractional area change; RVOT, right ventricular outflow tract; SBP, systolic blood pressure; TOF, tetralogy of Fallot; VA, ventricular arrhythmia.

from VA in those with NT-proBNP below the value $321 \mathrm{ng} / \mathrm{L}$ (figure 2).

\section{DISCUSSION}

This is the first larger study exploring the relationship between pregnancy and outcome in women corrected for TOF. We showed that pregnancy was associated with adverse long-term outcome, with higher prevalence of VA in patients who had experienced pregnancy independently of age. Importantly, our study showed that also a heterogeneous RV contraction pattern and higher values of NT-proBNP were associated with VA.

\section{Pregnancy and ventricular arrhythmia}

Our findings indicated that pregnancy relate to a higher incidence of VA. One of the main concerns and complication that occurs during adult life of patients with TOF is the incidence of VA, which is often the main cause behind sudden cardiac death. ${ }^{34}$ Several previous studies investigate the short-term outcome of pregnancy in women with TOF, showing a higher incidence of cardiovascular events during pregnancies, including mainly (supra) VA, ${ }^{9}$ heart failure and progressive RV dilatation. ${ }^{10}$ Predictors of complications were the use of cardiac medication before pregnancy, ${ }^{9} \mathrm{LV}$ dysfunction, severe pulmonary hypertension and severe pulmonic regurgitation with RV dysfunction. ${ }^{10}$ Occurrence of NSVT with hypotension and sinus bradycardia of pregnant woman with repaired TOF has also been described.$^{18} \mathrm{LV}$ dysfunction and pulmonic valve stenosis and/or regurgitation were not associated with higher prevalence of arrhythmias in our study. 
Table 3 Comparisons of female patients corrected for TOF without and with history of VA, and markers for VA adjusted for age

\begin{tabular}{|c|c|c|c|c|c|}
\hline & $\begin{array}{l}\text { TOF without VA } n=63 \\
(79 \%)\end{array}$ & $\begin{array}{l}\text { TOF with VA } n=17 \\
(21 \%)\end{array}$ & $P$ value & $\begin{array}{l}\text { OR } \\
(95 \% \mathrm{Cl})\end{array}$ & $P$ value \\
\hline Age, years & $36 \pm 9$ & $40 \pm 9$ & 0.08 & & \\
\hline Height, cm & $165 \pm 7$ & $166 \pm 9$ & 0.81 & & \\
\hline Weight, kg & $68 \pm 13$ & $63 \pm 10$ & 0.25 & & \\
\hline History of pregnancy, $\mathrm{n}(\%)$ & $39(61)$ & $16(94)$ & 0.02 & $13(1.5$ to 113.2$)$ & $0.02^{*}$ \\
\hline $\mathrm{HR}$, bpm & $68 \pm 11$ & $62 \pm 8$ & 0.13 & & \\
\hline SBP, mm Hg & $115 \pm 11$ & $115 \pm 13$ & 0.98 & & \\
\hline $\mathrm{DBP}, \mathrm{mm} \mathrm{Hg}$ & $68 \pm 9$ & $71 \pm 12$ & 0.44 & & \\
\hline QTC duration, ms & $458 \pm 31$ & $450 \pm 27$ & 0.52 & & \\
\hline Exercise capacity, W & $125 \pm 25$ & $140 \pm 26$ & 0.13 & & \\
\hline NYHA class & $1(1-3)$ & $1(1-2)$ & 0.66 & & \\
\hline NT-proBNP, ng/L & $139(30-465)$ & $211(127-836)$ & 0.007 & 1.4 (1.1 to 1.7$)$ & $0.017^{*}$ \\
\hline QRS duration, ms & $135(82-174)$ & $133(86-152)$ & 0.45 & & \\
\hline RV EDV, $\mathrm{mL}$ & $21.1 \pm 4.1$ & $22.7 \pm 3.6$ & 0.16 & & \\
\hline RV ESV, mL & $11.1 \pm 2.6$ & $11.8 \pm 2.5$ & 0.33 & & \\
\hline RV FAC, \% & $47 \pm 7$ & $47 \pm 8$ & 0.93 & & \\
\hline RV D3, cm & $7.3 \pm 0.7$ & $7.4 \pm 0.7$ & 0.54 & & \\
\hline $\mathrm{PV}$ vel, $\mathrm{m} / \mathrm{s}$ & $1.9 \pm 0.6$ & $1.8 \pm 0.4$ & 0.39 & & \\
\hline Mod-sev PV reg & $12(19 \%)$ & $2(12 \%)$ & 0.47 & & \\
\hline LV MD, ms & $43 \pm 13$ & $48 \pm 16$ & 0.24 & & \\
\hline LV GLS, \% & $-19.2 \pm 3.1$ & $-17.5 \pm 3.6$ & 0.10 & & \\
\hline $\mathrm{RV} \mathrm{MD}, \mathrm{ms}$ & $39 \pm 14$ & $50 \pm 8$ & $\begin{array}{l}0.009 \\
0.016\end{array}$ & $\begin{array}{l}2.1(1.3 \text { to } 7.5) \\
5.7(3.5 \text { to } 9.2)\end{array}$ & $\begin{array}{l}0.01^{*} \\
0.03 \dagger\end{array}$ \\
\hline RV GLS, \% & $-19.7 \pm 4.1$ & $-18.3 \pm 4.1$ & 0.28 & & \\
\hline RVOT, cm & $2.9 \pm 0.4$ & $3.1 \pm 0.6$ & 0.31 & & \\
\hline LVEF, \% & $56 \pm 9$ & $54 \pm 8$ & 0.39 & & \\
\hline
\end{tabular}

Data are presented as mean $\pm \mathrm{SD}$ or median with range, as appropriate; $\mathrm{p}$ value from Student's t-test or Mann-Whitney $\mathrm{U}$ test as appropriate, and multivariable logistic regression.

${ }^{*}$ Adjusted for age at VA.

†Adjusted for age at echocardiography.

DBP, diastolic blood pressure; EDV, end-diastolic volume; ESS, end-systolic strain; ESV, end-systolic volume; GLS, global longitudinal strain; HR, heart rate; LV, left ventricular; LVEF, left ventricular ejection fraction; MD, mechanical dispersion; NT-proBNP, N-terminal pro-brain natriuretic peptide; NYHA, New York Heart Association classification; PV, pulmonary valve; RV, right ventricular; RV D3, right ventricular longitudinal diameter; RV FAC, right ventricular fractional area change; RVOT, right ventricular outflow tract; SBP, systolic blood pressure; TOF, tetralogy of Fallot; VA, ventricular arrhythmia.

A recent study showed no deleterious effects of pregnancy on RV volumes and aortic dimensions using cardiovascular magnetic resonance (CMR) measured before and at least 6 months after pregnancy in women with repaired TOF. ${ }^{19}$ In contrast, another study observed an accelerated rate of RV remodelling with an increase in RV end-diastolic volume measured by CMR after pregnancy, without deterioration of the RV systolic function. ${ }^{20}$ Echocardiography in our study did not detect any clear change in the dimension of the RV after pregnancy; with all the limitations connected to the use of echocardiography compared with CMR, which is currently the gold standard for volumetric measurements, our findings suggest that pregnancy has no significant effects on RV function and dimensions that are easily detectable with echocardiography.

\section{Risk markers of VA}

TOF is so far been perceived to be predominantly RV disease. In our study, none of the measures of LV were associated with VA. Mechanical dispersion in the LV has been shown to be a powerful marker of ventricular arrhythmias in previous studies. ${ }^{212}$

In our study, a longer QRS duration did not relate to VA in patients corrected for TOF, as previously showed in other studies, where a QRS duration $>180 \mathrm{~ms}$ was a risk marker of cardiac event. ${ }^{4}$ In a similar way, pulmonary regurgitation was not associated with VA. Only a low percentage of our 


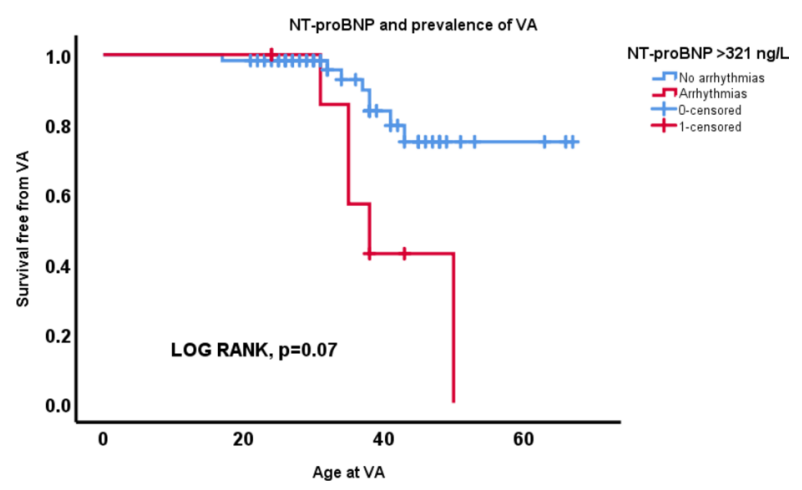

Figure 2 NT-proBNP and risk of ventricular arrhythmias. Kaplan-Meier plot shows that NT-proBNP values $>321 \mathrm{ng} / \mathrm{L}$ (normal values $<170 \mathrm{ng} / \mathrm{L}$ ) help with discrimination of female patients corrected for TOF with significantly higher risk of presenting VA, also when adjusted for age at arrhythmic event. NT-proBNP, N-terminal pro-brain natriuretic peptide; TOF, tetralogy of Fallot; VA, ventricular arrhythmia.

patients had moderate to severe pulmonary regurgitation (table 3); the longest QRS duration measured in our cohort was $172 \mathrm{~ms}$, which was lower than the cut-off value previously showed. ${ }^{4}$ Differences between patient populations might be due to a relatively young and healthy population in our study and may explain the different results.

Greater longitudinal diameter of the RV (D3) was the only conventional echocardiographic parameter that was significantly higher in mothers compared with nulliparous. This result was not confirmed by further analysis comparing nulliparous women with women with only one pregnancy, indicating no obvious remodelling of the RV during pregnancy. Our results partially support the results from a previous study, ${ }^{19}$ using CMR as the main diagnostic method and showing that pregnancy was not associated with a significant deterioration in RV volume.

RV mechanical dispersion was associated with VA, also when adjusted for age at VA event and age at echocardiography. RV mechanical dispersion was associated with VA, also when adjusted for age at VA event and age at echocardiography. RV mechanical dispersion has not previously been reported as a marker of VA in patients with TOF, but has been reported in other cardiac diseases affecting the RV such as arrhythmogenic right ventricular cardiomyopathy. ${ }^{1723}$ A variable grade of electromechanical dyssynchrony is expected after surgical repair in TOF, manifesting as prolonged QRS duration and right bundle branch block at EKG. ${ }^{24}$ Furthermore, higher RV mechanical dispersion values have been reported in TOF after surgical repair, reflecting electromechanical dyssynchrony severity and the underlying pathophysiology. ${ }^{25}$ Our study and the previous ones concur in showing that surgical repair is followed by a more severe grade of electromechanical dyssynchrony, manifesting with higher RV strain and mechanical dispersion, and giving higher risk of VA. These finding is also in line with previous reports showing RV mechanical dispersion, possibly reflecting myocardial fibrosis as a marker of VA in patients with arrhythmogenic right ventricular cardiomyopathy. ${ }^{23} 26$
NT-proBNP was a marker of VA independent of age. In particular, values of NT-proBNP $>321 \mathrm{ng} / \mathrm{L}$ (upper limit of $170 \mathrm{ng} / \mathrm{L}$ ) related to a higher odds of VA, and every 50 -unit increment of NT-proBNP increased the odds of VA by $40 \%$. A systematic review of 49 other studies showed that BNP levels were elevated and correlated significantly with RV enddiastolic dimensions and severity of pulmonary valve regurgitation in patients corrected for TOF. ${ }^{27}$ Our study supports the relation between NT-proBNP levels and incidence of arrhythmias, which may indicate that this parameter can be helpful in future evaluation of patients corrected for TOF.

\section{Clinical implications}

Importantly, this study suggests that number of pregnancies was associated with risk of VA in patients corrected for TOF. This information should be validated in future studies since this is of uppermost importance in preconception counselling of these patients.

Assessment of NT-proBNP together with RV mechanical dispersion might become useful parameters to consider in the VA risk stratification of patients operated for TOF.

\section{Study limitations}

This was a cross-sectional study with retrospective adjudication of outcome with associated limitations. We cannot derive causal inference. The patient population included in our study consists of a limited number of cases at a relatively young age. Among all patients, only one of them had severe ventricular arrhythmias without previously experiencing pregnancy. For this reason, there was a wide CI for the OR. The effect size should be interpreted with caution, and the test merely suggests that the odds for adverse outcome increased. In the same way, assessment of the impact of number of pregnancies was less robust than analysis grouping all women with previous pregnancy. Nulliparous women were significantly younger than mothers. A possible cause for the lower prevalence of VA registered in nulliparous women operated for TOF could be that cardiac remodelling and consequently risk of arrhythmias is progressive and it might increases with age. Importantly, age and pregnancy are closely related to each other, as parity inevitably follows age. Although we adjusted our statistical analyses for the differences in age, it is impossible to separate those two characteristics completely. Patients with more pronounced cardiac disease in the present study were more likely to have implantable cardiac devices, and many of these were not eligible for cardiac MRI. Therefore, the subgroup eligible for MRI represented a non-representative selection that was not included in the present analysis. This study was not designed to include CMR data, as only a subset of patients had CMR data due to contraindications or to personal reasons. Future studies should include CMR providing the most robust RV data in patients with TOF.

\section{CONCLUSIONS}

History of pregnancy was associated with higher prevalence of VA among women with surgically corrected TOF. 
The higher prevalence of severe ventricular arrhythmias in women, particularly after experienced pregnancy, may be of clinical importance despite the limited number of patients in this study. RV mechanical dispersion and NT-proBNP were also age-independent markers of VA. Larger and prospective studies are needed before we can advise against pregnancy in these patients. However, these important findings should be considered in risk stratification and pregnancy counselling of women operated on for TOF.

Acknowledgements We thank all the patients who participated in this study.

Contributors $\mathrm{AQ}$ : acquired data, analysed data, performed statistical analysis, writing. $\mathrm{OHL}$ : analysed data, performed statistical analysis, made critical revision of the manuscript. EN: designed the study, made critical revision of the manuscript for important intellectual content. CdL: conceived and designed the study, made critical revision of the manuscript for important intellectual content. KT: acquired data, made critical revision of the manuscript for important intellectual content. HLL: conceived and designed the research, made critical revision of the manuscript for important intellectual content. HS: acquired data, made critical revision of the manuscript for important intellectual content. GE: acquired data, made critical revision of the manuscript for important intellectual content. TE: handling the funding, made critical revision of the manuscript. KHH: analysed data, performed statistical analysis, made critical revision of the manuscript. MEE: conceived and designed the research, made critical revision of the manuscript for important intellectual content, handling funding and supervision, writing.

Funding This study was supported by the South-Eastern Norway Regional Health Authority (NR 2017103).

Competing interests None declared.

Patient consent for publication Not required.

Ethics approval The study was carried out according to the principles of the Declaration of Helsinki. This protocol was approved by the Regional Committees for Medical Research Ethics South East D (REK sør-øst D, reference number 2017/383) and the Oslo University Hospital Information Security and Privacy Office (number 19/09499).

Provenance and peer review Not commissioned; externally peer reviewed.

Data availability statement All data relevant to the study are included in the article or uploaded as online supplemental information. Researchers interested in the data, methods or analysis can contact the corresponding author for more information.

Open access This is an open access article distributed in accordance with the Creative Commons Attribution Non Commercial (CC BY-NC 4.0) license, which permits others to distribute, remix, adapt, build upon this work non-commercially, and license their derivative works on different terms, provided the original work is properly cited, appropriate credit is given, any changes made indicated, and the use is non-commercial. See: http://creativecommons.org/licenses/by-nc/4.0/.

Correction notice This article has been corrected since it first published. The provenance and peer review statement has been included

\section{ORCID iDs}

Alessia Quattrone http://orcid.org/0000-0001-8915-2630

Kristina Haugaa http://orcid.org/0000-0002-4900-0453

\section{REFERENCES}

1 Nollert G, Fischlein T, Bouterwek S, et al. Long-term survival in patients with repair of tetralogy of Fallot: 36-year follow-up of 490 survivors of the first year after surgical repair. J Am Coll Cardiol 1997;30:1374-83.

2 Lindberg HL, Saatvedt K, Seem E, et al. Single-center 50 years experience with surgical management of tetralogy of Fallot. Eur $J$ Cardiothorac Surg 2011;40:538-42.

3 Cuypers JAAE, Menting ME, Konings EEM, et al. Unnatural history of tetralogy of Fallot: prospective follow-up of 40 years after surgical correction. Circulation 2014;130:1944-53.

4 Gatzoulis MA, Balaji S, Webber SA, et al. Risk factors for arrhythmia and sudden cardiac death late after repair of tetralogy of Fallot: a multicentre study. Lancet 2000;356:975-81.
5 van Grootel RWJ, van den Bosch AE, Baggen VJM, et al. The prognostic value of myocardial deformation in adult patients with corrected tetralogy of Fallot. J Am Soc Echocardiogr 2019;32:866-75.

6 Sanghavi M, Rutherford JD. Cardiovascular physiology of pregnancy. Circulation 2014;130:1003-8.

7 Estensen ME, Beitnes JO, Grindheim G, et al. Altered maternal left ventricular contractility and function during normal pregnancy. Ultrasound Obstet Gynecol 2013;41:659-66.

8 Estensen M-E, Grindheim G, Remme EW, et al. Systemic arterial response and ventriculo-arterial interaction during normal pregnancy. Am J Hypertens 2012;25:672-7.

9 Balci A, Drenthen W, Mulder BJM, et al. Pregnancy in women with corrected tetralogy of Fallot: occurrence and predictors of adverse events. Am Heart J 2011;161:307-13.

10 Veldtman GR, Connolly HM, Grogan M, et al. Outcomes of pregnancy in women with tetralogy of Fallot. J Am Coll Cardiol 2004;44:174-80.

11 Pedersen CT, Kay GN, Kalman J, et al. EHRA/HRS/APHRS expert consensus on ventricular arrhythmias. Europace 2014;16:pp.:1257-83.

12 Bruce RA, Blackmon JR, Jones JW, et al. Exercising testing in adult normal subjects and cardiac patients. 1963. Ann Noninvasive Electrocardiol 2004;9:742-56.

13 Badano LP, Miglioranza MH, Edvardsen T, et al. European Association of Cardiovascular Imaging/Cardiovascular Imaging Department of the Brazilian Society of Cardiology recommendations for the use of cardiac imaging to assess and follow patients after heart transplantation. Eur Heart J Cardiovasc Imaging 2015;16:919-48.

14 Lang RM, Badano LP, Mor-Avi V, et al. Recommendations for cardiac chamber quantification by echocardiography in adults: an update from the American Society of Echocardiography and the European Association of Cardiovascular Imaging. Eur Heart J Cardiovasc Imaging 2015;16:233-71.

15 Edvardsen T, Haugaa $\mathrm{KH}$. Imaging assessment of ventricular mechanics. Heart 2011;97:1349-56.

16 Sarvari SI, Haugaa KH, Anfinsen O-G, et al. Right ventricular mechanical dispersion is related to malignant arrhythmias: a study of patients with arrhythmogenic right ventricular cardiomyopathy and subclinical right ventricular dysfunction. Eur Heart $J$ 2011;32:1089-96.

17 Haugaa KH, Basso C, Badano LP, et al. Comprehensive multimodality imaging approach in arrhythmogenic cardiomyopathyan expert consensus document of the European Association of Cardiovascular Imaging. Eur Heart J Cardiovasc Imaging 2017; 18:237-53.

18 Ito S, Stout KK, Robinson MR. Non-sustained ventricular tachycardia in a pregnant woman with repaired tetralogy of Fallot: a challenging case. Int J Cardiol 2016;203:1133-4.

19 Cauldwell M, Quail MA, Smith GS, et al. Effect of pregnancy on ventricular and aortic dimensions in repaired tetralogy of Fallot. $J \mathrm{Am}$ Heart Assoc 2017;6:e005420.

20 Egidy Assenza G, Cassater D, Landzberg M, et al. The effects of pregnancy on right ventricular remodeling in women with repaired tetralogy of Fallot. Int J Cardiol 2013;168:1847-52.

21 Haugaa KH, Smedsrud MK, Steen T, et al. Mechanical dispersion assessed by myocardial strain in patients after myocardial infarction for risk prediction of ventricular arrhythmia. JACC CardiovasC Imaging 2010;3:247-56.

22 Haugaa KH, Grenne BL, Eek CH, et al. Strain echocardiography improves risk prediction of ventricular arrhythmias after myocardial infarction. JACC Cardiovasc Imaging 2013;6:841-50.

23 Lie Øyvind H, Rootwelt-Norberg C, Dejgaard LA, et al. Prediction of life-threatening ventricular arrhythmia in patients with arrhythmogenic cardiomyopathy: a primary prevention cohort study. JACC Cardiovasc Imaging 2018;11:1377-86.

24 Mueller M, Rentzsch A, Hoetzer K, et al. Assessment of interventricular and right-intraventricular dyssynchrony in patients with surgically repaired tetralogy of Fallot by two-dimensional speckle tracking. Eur J Echocardiogr 2010;11:786-92.

25 Yim D, Hui W, Larios G, et al. Quantification of right ventricular electromechanical dyssynchrony in relation to right ventricular function and clinical outcomes in children with repaired tetralogy of Fallot. J Am Soc Echocardiogr 2018;31:822-30.

26 Leren IS, Saberniak J, Haland TF, et al. Combination of ECG and echocardiography for identification of arrhythmic events in early ARVC. JACC Cardiovasc Imaging 2017;10:503-13.

27 Eindhoven JA, van den Bosch AE, Jansen PR, et al. The usefulness of brain natriuretic peptide in complex congenital heart disease: a systematic review. J Am Coll Cardiol 2012;60:2140-9. 


\section{Correction: Impact of pregnancy and risk factors for ventricular arrhythmias in women with tetralogy of Fallot}

Quattrone A, Lie $\mathrm{OH}$, Nestaas E, et al. Impact of pregnancy and risk factors for ventricular arrhythmias in women with tetralogy of Fallot. Open Heart 2021;8:e01400. doi: 10.1136/openhrt-2020-001400.

This article has been corrected since it was first published. The provenance and peer review statement has been included.

Open access This is an open access article distributed in accordance with the Creative Commons Attribution Non Commercial (CC BY-NC 4.0) license, which permits others to distribute, remix, adapt, build upon this work non-commercially, and license their derivative works on different terms, provided the original work is properly cited, appropriate credit is given, any changes made indicated, and the use is non-commercial. See: http://creativecommons.org/licenses/by-nc/4.0/.

C Author(s) (or their employer(s)) 2021. Re-use permitted under CC BY-NC. No commercial re-use. See rights and permissions. Published by BMJ.

Open Heart 2021;8:e001400corr1. doi:10.1136/openhrt-2020-001400corr1

(A) Check for updates 